\author{
Joep M. Droogh \\ Ingeborg M. Noppers \\ Jaap E. Tulleken \\ John H. Meertens \\ Jack J. Ligtenberg \\ Wilma E. Monteban-Kooistra \\ Jan G. Zijlstra
}

\section{Comment on Mackenzie and Woodhouse: C-reactive protein concentrations during bacteraemia: a comparison between patients with and without liver dysfunction}

Accepted: 20 December 2006

Published online: 30 January 2007

(C) Springer-Verlag 2007

An author's reply to this comment is available at: http://dx.doi.org/10.1007/ s00134-006-0525-7

Sir: With interest we read Mackenzie and Woodhouse's paper about serum C-reactive protein (CRP) levels in patients with and without liver dysfunction during bacteraemia [1]. The authors concluded that patients with biochemical evidence of liver disease show significantly lower serum CRP levels during bacteraemia than patients without liver dysfunction. This remarkable result was only achieved when patients with biopsy-proven liver cirrhosis were included in the analysis. When cirrhotic patients were excluded, however, and patients with liver dysfunction, defined as an elevated plasma bilirubin level and increased prothrombin time, were compared with controls, betweengroup differences did not reach statistical significance. Therefore, we feel that from the available data it cannot be concluded that patients with liver diseases, in general, generate lower serum CRP levels during bacteraemia.

As multiple studies have shown greater CRP production in cirrhotic non-infected patients than in healthy controls [2, 3], it could be argued that cirrhotic patients produce less CRP during periods of infection. However, a recent large study in critically ill subjects reported that CRP levels during infection in cirrhotic patients did not significantly differ from CRP levels in non-cirrhotic patients [4]. Also, no differences were found in relation to the severity of the cirrhosis. Because interleukin-6 stimulates hepatocytes to produce CRP, an interesting study to aid the understanding of these apparently conflicting results would be to relate the interleukin-6 to CRP levels in cirrhotic patients. However, as far as we know, this has not been done.

Finally, we believe that the use of CRP as a valuable screening test for infection in the ICU has certain limitations. The decision on starting antibiotics must be individualized and not be based on a certain CRP level. It should be based on suspicion of the presence of infection, the stability of the patient's clinical condition, the presence of comorbidity and the risk of death or complications.

\section{References}

1. Mackenzie I, Woodhouse J (2006) C-reactive protein concentrations during bacteraemia: a comparison between patients with and without liver dysfunction. Intensive Care Med 32:1344-1351

2. Campillo B, Sherman E, Richardet JP, Bories PN (2001) Serum leptin levels in alcoholic liver cirrhosis: relationship with gender, nutritional status, liver function and energy metabolism. Eur J Clin Nutr 55:980-988

3. Tilg H, Wilmer A, Vogel W, Herold M, Nolchen B, Judmaier G, Huber C (1992) Serum levels of cytokines in chronic liver diseases. Gastroenterology 103:264-274

4. Bota DP, Van Nuffelen M, Zakariah AN, Vincent JL (2005) Serum levels of $\mathrm{C}$-reactive protein and procalcitonin in critically ill patients with cirrhosis of the liver. J Lab Clin Med 146:347-351

J. M. Droogh · I. M. Noppers ·

J.E. Tulleken $(\varangle) \cdot$ J.H. Meertens ·

J. J. Ligtenberg · W. E. Monteban-Kooistra •

J. G. Zijlstra

University Medical Center Groningen,

Intensive \& Respiratory Care Unit (ICB), PO Box 30.001, 9700 RB Groningen,

Netherlands

e-mail: j.e.tulleken@ int.umcg.nl

Tel.: +31-50-3616161

Fax: +31-50-3613216 